\title{
Linkage and Branch Determination of N-linked Oligosaccharides \\ Using Sequential Degradation/Closed-Ring Chromophore Labeling/Negative Ion Trap Mass Spectrometry
}

\author{
Hsing-Ling Cheng, Pei-Jing Pai, and Guor-Rong Her \\ Department of Chemistry, National Taiwan University, Taipei, Taiwan, R.O.C
}

\begin{abstract}
A method based on sequential degradation, $p$-aminobenzoic ethyl ester (ABEE) closed-ring labeling, and negative ion electrospray ionization tandem mass spectrometry is presented for the study of linkage and branch determination for $\mathrm{N}$-linked oligosaccharides. Closed-ring labeling provides greater linkage information than the more popular open-ring reductive amination approach. In addition, after high-performance liquid chromatography (HPLC) separation, closed-ring labeling allows for regeneration of the underivatized oligosaccharide, a requirement for alkaline sequential degradation. The analytical scheme presented here uses HPLC separation of closed-ring labeled oligosaccharides to resolve the mixture into individual forms that undergo subsequent structural analysis by negative ion tandem mass spectrometry. To facilitate complete structural analysis, particularly for larger sugars, the closed-ring labels are removed and the sugars are sequentially degraded by controlled alkaline hydrolysis. It is noteworthy that for sugars containing sialic acid moieties, a protecting group must be used to stabilize sialic acid groups during sequential alkaline degradation. This described approach was applied to two high mannose oligosaccharides M5G2, M6G2 cleaved from the ribonuclease B and a complex oligosaccharide A2 cleaved from transferrin. (J Am Soc Mass Spectrom 2007, 18, 248-259) (c) 2007 American Society for Mass Spectrometry
\end{abstract}

$\mathrm{T}$ The amino acid sequence alone is generally insufficient to describe protein function. The biologically active forms of mature proteins are often post-translationally modified and these modifications typically influence protein function. Glycosylation is a predominant modification mechanism. It has been estimated that $60-90 \%$ of all mammalian proteins are glycosylated [1]. The carbohydrate chains play critical roles in numerous biological processes, including fertilization, immune response, viral replication, parasitic inflection, cell-cell adherence, degradation of blood clots, and inflammation, for example [1-4]. The structural diversity inherent in the sugar moieties of a glycoprotein enables subtle changes in protein shape, charge, and volume, which can affect function both temporally and spatially. To achieve a full understanding of the function of a glycoprotein, a detailed characterization of its glycan structure is imperative.

Structural elucidation of complex carbohydrates requires determination of monosaccharide composition, sequence, branching pattern, glycosidic linkages, and

Published online November 2, 2006

Address reprint requests to Dr. Guor-Rong Her, National Taiwan University, Department of Chemistry, Taipei 10764, Taiwan. E-mail:grher@ ntu.edu.tw anomeric configuration. Nuclear magnetic resonance (NMR) comes close to providing complete structural analysis, although the amount of sample required and difficulty with analyzing complex mixtures limits the utility of NMR, particularly for proteomics applications. In recent years, mass spectrometry (MS) has become a key tool for structural analysis of carbohydrates. Several mass spectrometric techniques have been proved to be useful analytical tools for the determination of oligosaccharide structure. All of these techniques have the advantages over traditional methods [5], such as low sample consumption and are less time-consuming. Matrix-assisted laser desorption/ionization (MALDI) and electrospray ionization (ESI) are now the prominent mass spectrometric ionization techniques for the analysis of biomolecules. These ionization methods provide the direct analysis of polar and thermally labile biomolecules. In structural analysis of carbohydrates, native and derivatized oligosaccharides have been analyzed by MALDI [5-14]. Metal ion coordinated [15, 16] or chemically derivatized [17-34] oligosaccharides have been used for ESI analysis. Among those approaches, the method based on MALDI time-of flight/time-offlight (TOF/TOF) tandem mass spectrometry provides good sensitivity and cross-ring cleavage because of the 
use of high-energy collision-induced dissociation (heCID) [8-14].

Most glycoproteins carry a heterogeneous mixture of oligosaccharides and even a single glycosylation site of a pure glycoprotein is often heterogeneously glycosylated. To examine single carbohydrate forms in heterogeneous mixtures, chromatographic separation is needed. However, because of the lack of significant chromophore, carbohydrates are difficult for UV or fluorescence detection after high-performance liquid chromatography (HPLC) separation. The formation of chromophore-labeled derivatives is a common practice and allows detection of glycans in subpicomolar concentrations. Different derivatives such as 2-aminopyridine (2-AP), 2-aminobenzoic acid (AA), 4-aminobenzoic acid ethyl ester (ABEE), and 2-aminoacridone (2-AMAC) have been introduced for highly sensitive detection [35]. Our earlier study suggests that closed-ring derivatization provides more structural information on linkage and anomeric configuration than open-ring (reductive amination) under negative ion MS/MS [28]. More recently, the technique was extended to oligosaccharides, where all linkages and branch points were unambiguously assigned by the negative ion ESI-MS ${ }^{2}$ and $\mathrm{MS}^{3}$ experiments using $\mathrm{ABEE}$ closed-ring labeled derivatives [30]. Nevertheless, further study revealed that linkage information near the nonreducing end was either weak or not available in the $\mathrm{MS}^{2}$ or $\mathrm{MS}^{3}$ mass spectra if the oligosaccharide was larger than a hexasaccharide. In addition, $\mathrm{MS}^{4}$ or above is not very practical for most applications. One possible solution for the above problem is to reduce the size of the oligosaccharide from the reducing end.

Both enzymatic and chemical methods have been used for carbohydrate degradation. In enzymatic methods, exoglycosidases cleave the glycan stepwise from the nonreducing end, but not from the reducing end. Endoglycosidases randomly cleave internal glycosidic linkages; therefore, chemical methods must be considered to achieve the intended degradation. Chemical degradation involves either acid or basic hydrolysis. Both methods have been used as degradation methods for oligosaccharide and polysaccharide analysis [3644]. In acid hydrolysis, carbohydrates are cleaved randomly into a mixture of oligosaccharides. In contrast, basic hydrolysis progressively cleaves a monosaccharide unit from the reducing end of the oligosaccharides through $\beta$-elimination [36]. Under appropriate alkaline conditions, it has been demonstrated that monosaccharides can be removed sequentially from the reducing end [43].

Many, if not most, N-linked oligosaccharides are larger than hexasaccharides. An approach based on alkaline degradation, ABEE closed-ring labeling and negative ion trap mass spectrometry were proposed for the analysis of linkage as well as branch position of $\mathrm{N}$-linked oligosaccharides. The utility of the approach is demonstrated in this report with two high mannose oligosaccharides M5G2, M6G2 cleaved from the ribonu- clease B and a complex oligosaccharide A2 cleaved from transferrin.

\section{Experimental}

\section{Materials}

Ethyl 4-aminobenzoate (ABEE), 2-mercaptoethanol, formic acid, trifluoroacetic acid (TFA), glacial acetic acid, sodium carbonate, dimethyl sulfoxide (DMSO), triphenylphosphine, pyridine, ethanolamine, human serum transferring, and ribonuclease B (RNase B) were purchased from Sigma Chemical (St. Louis, MO). 3'-Sialyllactose and 6'-sialyllactose were obtained from Glyko, Inc. (Novato, CA). Peptide-N-glycanase F (PNGase F) was purchased from Boehringer Mannheim $\mathrm{GmbH}$ (Mannheim, Germany). HPLC grade methanol and acetonitrile were obtained from LAB-SCAN Analytical Science (Labscan Ltd. Dublin, Ireland). Deionized (18 M $\Omega$ ) water (Milli-Q water system, Millipore Inc., Bedford, MA) was used in the preparation of samples and buffer solutions. The buffer solution was filtered through a $0.45 \mu \mathrm{m}$ membrane filter (Gelman Sciences, Ann Arbor, MI) before use.

\section{Preparation of N-linked Glycans and Chromophore Labeling}

Oligosaccharides were released from $400 \mu \mathrm{g}$ ribonuclease $\mathrm{B}$ and $800 \mu \mathrm{g}$ transferrin by means of PNGase F digestion [45, 46]. A graphitized carbon cartridge (Alltech Associates, Lancashire, UK) $[30,46]$ was used to purify the glycans.

Oligosaccharides were ABEE closed-ring labeled by using the glycosylamine approach [30]. ${ }^{\circ}$ Dried $^{\circ}$ lyophilized oligosaccharides were added to a volume $(15 \mu \mathrm{L})$ of $0.1 \mathrm{M}$ ABEE solution (2 $\mathrm{mg}$ of the ABEE reagent dissolving in a 3:7 ( $\mathrm{vol} / \mathrm{vol})$ mixture of glacial acetic acid and DMSO) in a clean tube. The solution was incubated at $90^{\circ} \mathrm{C}$ for $10 \mathrm{~h}$. For sialylated oligosaccharides, the temperature was reduced to $65^{\circ} \mathrm{C}$. The derivatives were purified by being passed through an Oasis cartridge (Waters Associates, Milford, MA), followed by lyophilization.

\section{Alkaline Degradation}

Dried lyophilized oligosaccharide was dissolved in 50 $\mu \mathrm{L} 20 \mathrm{mM} \mathrm{NaOH}$ and incubated at $60^{\circ} \mathrm{C}$ for a period between 8 and $24 \mathrm{~h}$.

\section{Protection of Sialylated Oligosaccharides}

Sialylated oligosaccharides can be readily converted into 2-alkyl-1,3-oxazoline derivatives by reaction with ethanolamine in the presence of approximately 3 equivalents of triphenylphosphine and triethylamine in acetonitrile-pyridine (1:1) for $4 \mathrm{~h}$ at room temperature. 

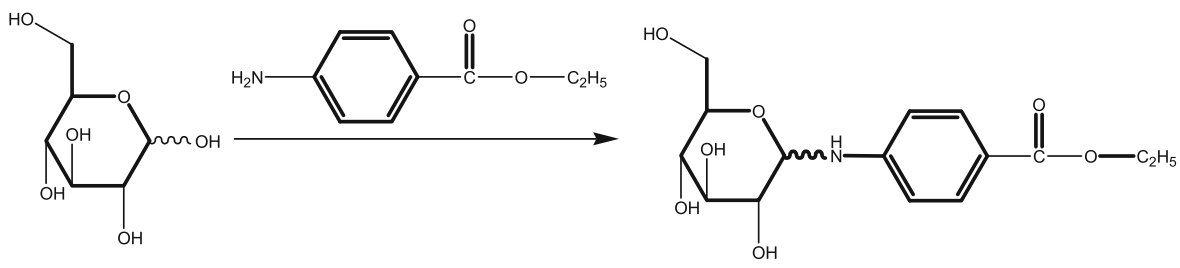

Scheme 1. The reaction of ABEE closed-ring labeling of oligosaccharide.

\section{HPLC Separation of N-linked Glycans}

The chromatography system consisted of two model LC-10AD pumps (Shimadzu, Kyoto, Japan), an Acurate microflow mixer (LC Packings, San Francisco, CA), a Rheodyne model 7125 injection valve (Rheodyne, Cotati, CA), and a Rainin Dynamax UV-C UV detector set at $305 \mathrm{~nm}$ (Rainin, MA). Chromatograms were recorded on a Pentium-PC using SISC PC Integrator software (Scientific Information Service Corp., Taipei, Taiwan).

ABEE closed-ring labeled N-linked glycans were separated on an amino spherisorb column $(4 \mathrm{~mm}$ i.d. $\times$ $25 \mathrm{~cm}$; particle size, $5 \mu \mathrm{m}$; Waters Associates). The mobile phases were deionized water (solvent A) and acetonitrile (solvent B). The flow rate was set at 1 $\mathrm{mL} / \mathrm{min}$. The following elution conditions were used: (step 1) 20\% A, 80\% B equilibration conditions; (step 2) $80-40 \%$ B over 40 min, linear gradient; (step 3) washing with $100 \% \mathrm{~A}$ for $10 \mathrm{~min}$; (step 4) reequilibration for 15 min.

\section{Delabeling of Chromophore}

Dried lyophilized ABEE closed-ring labeled oligosaccharide was dissolved in $2 \%$ acetic acid solution and incubated at $65^{\circ} \mathrm{C}$ for $48 \mathrm{~h}$. For sialylated oligosaccharides, the reaction condition was modified to $37^{\circ} \mathrm{C}$ for $2.5 \mathrm{~h}$ to minimize the cleavage of sialic acids.

\section{Mass Spectrometry}

All the mass spectrometry experiments were performed on a Finnigan LTQ ion trap mass spectrometer (Finnigan Corp., San Jose, CA) with the standard Finnigan ESI source in negative ion mode at a voltage of $-4 \mathrm{kV}$. Samples were infused by syringe pump at a rate of 1 $\mu \mathrm{L} / \mathrm{min}$ and nebulized with dry nitrogen. The heated capillary was maintained at $200{ }^{\circ} \mathrm{C}$ for all experiments. Helium was introduced as the buffer/collision gas. For mass-analyzer collision-induced dissociation (CID), relative collision energies of $10-70 \%$ were used in $\mathrm{MS}^{n}$ experiments. The maximum ion injection time was set at $180 \mathrm{~ms}$ and three microscans were summed per scan.

\section{Results and Discussion}

In our earlier study, the linkages and branch points of oligosaccharide standard were unambiguously assigned based on the negative ion ESI-MS ${ }^{2}$ and MS $^{3}$ experiments of the ABEE closed-ring labeled deriva- $\operatorname{tives}^{\circ}\left(\text { Scheme }^{\circ} 1\right)^{\circ}[30]^{\circ}{ }^{\circ} \mathrm{To}^{\circ}$ extend $^{\circ}$ the ${ }^{\circ}$ approach $^{\circ}$ to ${ }^{\circ} \mathrm{N}$ linked glycans from glycoproteins, HPLC separation was required because N-linked glycans are often mixtures. ABEE closed-ring derivatives have shown better chromatographic behavior than open-ring derivatives on $^{\circ}$ an $^{\circ}$ amino $^{\circ}$ phase $^{\circ} \mathrm{HPLC}^{\circ}$ column $^{\circ}\left[27,{ }^{\circ} 28^{\circ} 30\right] .{ }^{\circ}$ Five peaks corresponding to M5G2, M6G2, M7G2, M8G2, and M9G2 were detected in the HPLC/UV chromatogram with peak ratios of $45,29,7,13$, and $6 \%$. After HPLC purification, the biantennary high-mannose heptasaccharide M5G2 was studied by negative ion tandem mass spectrometry. The $\mathrm{MS}^{2}$ spectrum of the ABEE closed-ring ${ }^{\circ}$ labeled ${ }^{\circ} \mathrm{M}_{5} \mathrm{G}_{2}{ }^{\circ}$ is ${ }^{\circ}$ shown $^{\circ}$ in ${ }^{\circ}$ Figure $^{\circ} 1 .^{\circ}$ The linkage- ${ }^{\circ}$ and ${ }^{\circ}$ branch-specific $^{\circ}$ fragment $^{\circ}$ ions $^{\circ}\left(\right.$ Table $\left.^{\circ} 1\right)$, proposed ${ }^{\circ} n^{\circ}{ }^{\circ}{ }^{\circ}$ previous $^{\circ}$ publication [30], ${ }^{\circ}$ were ${ }^{\circ}$ used to assign $^{\circ}$ the $^{\circ}$ linkages ${ }^{\circ}$ and $^{\circ}$ branch $^{\circ}$ points $^{\circ}$ of $^{\circ}$ M5G2..$^{\circ}$ The fragments corresponding to $C_{4}\left(\mathrm{~m} / z\right.$ 1030) and $C_{3}(\mathrm{~m} / \mathrm{z}$ 827 ) ions (Domon and Costello nomenclature for carbohydrate ${ }^{\circ}$ fragmentation ${ }^{\circ}$ is ${ }^{\circ}$ used $\left.^{\circ}[47]\right)^{\circ}$ indicate ${ }^{\circ}$ that ${ }^{\circ}$ both the reducing end and the next adjacent monosaccharide are $\mathrm{N}$-acetylhexosamines (HexNAc). The ${ }^{0,2} \mathrm{~A}_{5}-18$ ion $(\mathrm{m} / \mathrm{z}$ 1114) identifies the 1-4 linkage of the reducing end. The 1-4 linkage of the second HexNAc is revealed by the ${ }^{0,2} \mathrm{~A}_{4}\left(\mathrm{~m} / \mathrm{z}\right.$ 929) and the ${ }^{0,2} \mathrm{~A}_{4}-18(\mathrm{~m} / \mathrm{z} 911)$ fragments. The $\mathrm{C}_{3} / \mathrm{Z}_{3 \beta}-\mathrm{H}\left(\mathrm{m} / \mathrm{z}\right.$ 647) and $\mathrm{C}_{2 \alpha}(\mathrm{m} / z$ 503) fragments indicate a branch point at the third saccharide, which is a hexose (Hex). In addition, the $\mathrm{C}_{3} / \mathrm{Z}_{3 \beta}-\mathrm{H}(\mathrm{m} / \mathrm{z} 647)$ fragment represents the loss of a hexose (180 Da) from the $C_{3}(\mathrm{~m} / \mathrm{z}$ 827) fragment, which indicates that the hydroxy group at the 3 position of the branched sugar is substituted with a hexose residue. The intensity of the $\mathrm{C}_{3} / \mathrm{Z}_{3 \beta}-\mathrm{H}$ fragment was too low to observe further cross-ring and glycosidic bond cleavages. Based on the $\mathrm{MS}^{2}$ data, the predicted structure of M5G2 is

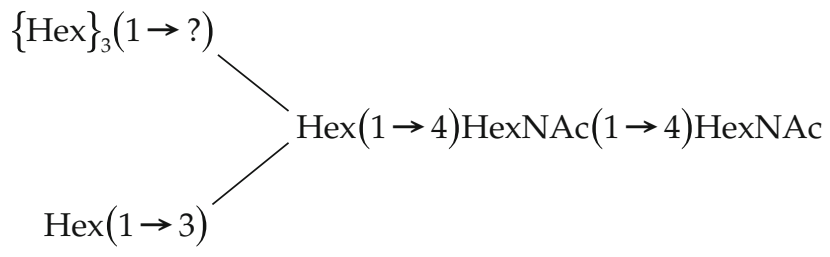

The symbols Hex and HexNAc stand for hexose and $\mathrm{N}$-acetylhexosamine, respectively.

The linkage information near the nonreducing end is not clear in the CID spectra. Therefore, alkaline degradation was used to reduce the size of the oligosaccharide from the reducing end. However, it was observed that the chromophore-labeled glycan would prevent 


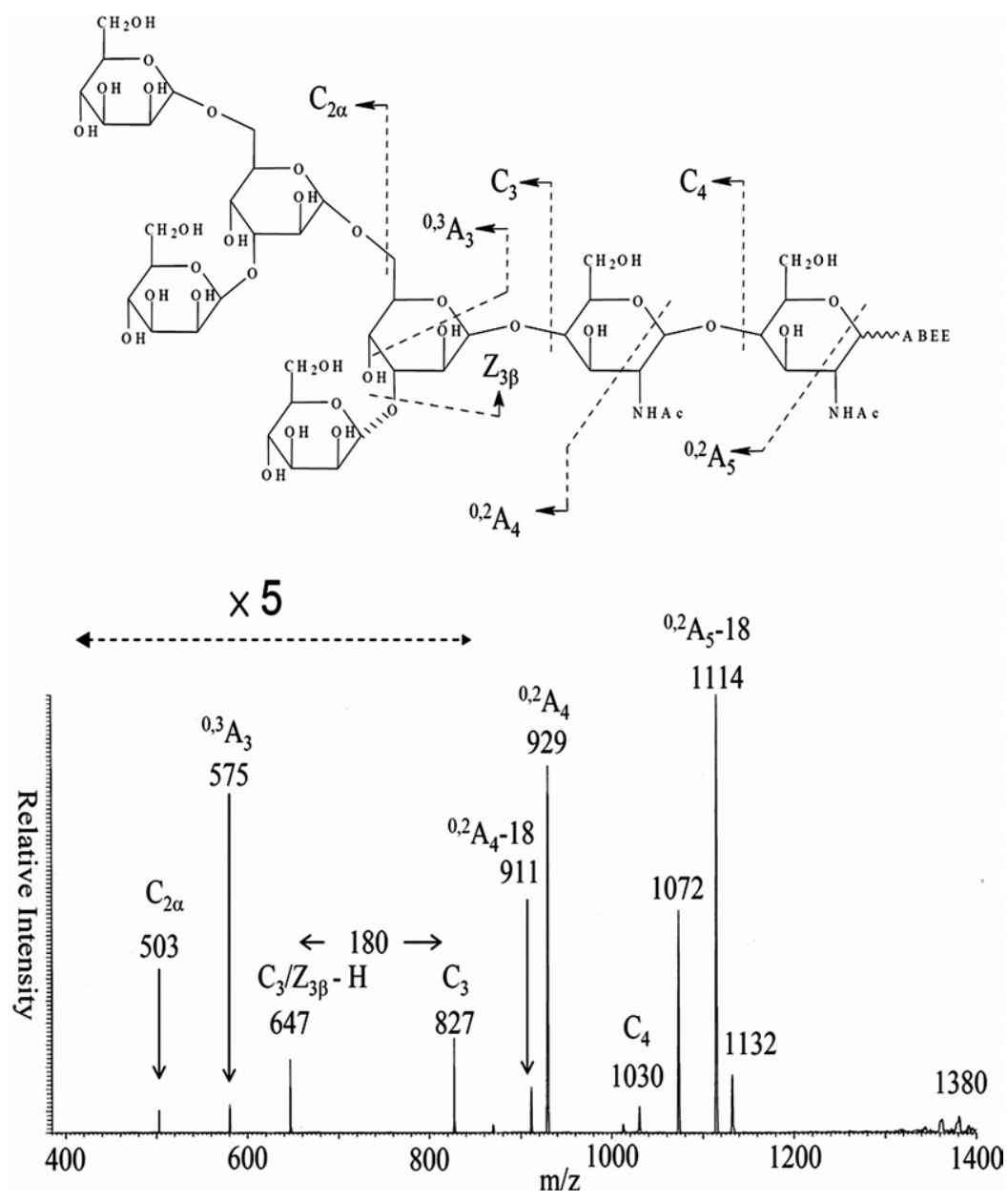

Figure 1. $\mathrm{MS}^{2}$ of the ABEE closed-ring labeled M5G2, $\mathrm{m} / \mathrm{z} 1380 \rightarrow$.

basic hydrolysis resulting from the formation of an acetal group at the reducing end. For this reason, delabeling is imperative before the degradation step. It is noteworthy that, unlike the open-ring reductive amination approach, closed-ring labeling makes the regeneration ${ }^{\circ}$ of $^{\circ}$ underivatized $^{\circ}$ oligosaccharide $^{\circ}$ possible $^{\circ}[26]$. After the HPLC separation, the underivatized oligosaccharides can be regenerated. A $2 \%$ acetic acid solution for 2 days at $65^{\circ} \mathrm{C}$ was found sufficient to remove the chromophore. The M5G and M5, obtained from M5G2 after a 14-h reaction period in $20 \mathrm{mM} \mathrm{NaOH}$, were labeled with $\mathrm{ABEE}$ and subjected to $\mathrm{MS}^{2}$ study. The $\mathrm{MS}^{2}$ spectrum of the ABEE closed-ring labeled M5G $(\mathrm{m} / \mathrm{z} 1177$, spectrum not shown) revealed that the intensity of the $\mathrm{C}_{3} / \mathrm{Z}_{3 \beta^{-}}-\mathrm{H}(\mathrm{m} / \mathrm{z}$ 647) ion was significantly higher ${ }^{\circ}$ than $^{\circ}$ that $^{\circ}$ in $^{\circ}$ Figure $^{\circ} 1 .^{\circ}$ Therefore, ${ }^{\circ}$ the ${ }^{\circ}$ fragment from $\mathrm{C}_{3} / \mathrm{Z}_{3 \beta}-\mathrm{H}$ cleavage $(\mathrm{m} / \mathrm{z} 647)$ was subjected to $\mathrm{MS}^{3}$ study, and the result (M5G, $m / z 1177 \rightarrow 647 \rightarrow$ ) is shown in $^{\circ}$ Table $^{\circ} 2 .^{\circ}$ The ${ }^{\circ}$ detection ${ }^{\circ}$ of ${ }^{\circ}$ the ${ }^{\circ} \mathrm{C}_{3}-18(\mathrm{~m} / \mathrm{z} 629),{ }^{0,3} \mathrm{~A}_{3}$ $(m / z 575)$ and ${ }^{0,4} \mathrm{~A}_{3}(m / z 545)$ ions and the absence of the ${ }^{0,2} \mathrm{~A}_{3}(\mathrm{~m} / \mathrm{z} 605)$ ion revealed that the linkages of the first branch of M5G2 are 1-6 and 1-3. It is worth noting that the presence of a 1-3 linkage at the first branch point is also supported by the presence of the $\mathrm{C}_{3} / \mathrm{Z}_{3 \beta}-\mathrm{H}$ ion. The $\mathrm{C}_{2} / \mathrm{Z}_{2}-\mathrm{H}(\mathrm{m} / \mathrm{z} 323)$ fragment represents the loss of a hexose $(180 \mathrm{Da})$ from the terminal trisaccharide $C_{2}(\mathrm{~m} / \mathrm{z}$

Table 1. Specific linkage fragment ions for ABEE closed-ring labeled linear and branched oligosaccharides ${ }^{\mathrm{a}}$

\begin{tabular}{|c|c|c|c|c|}
\hline Linkage & $\begin{array}{l}\text { Fragments of the } \\
\text { first linkage } \\
\text { (reducing end) }\end{array}$ & $\begin{array}{l}\text { Fragments other than } \\
\text { the reducing end }\end{array}$ & $\begin{array}{l}\text { Linkages at the } \\
\text { branch point }\end{array}$ & $\begin{array}{c}\text { Fragments for linkages at } \\
\text { branch points }\end{array}$ \\
\hline $1-2$ & ${ }^{0,2} \mathrm{X},{ }^{0,4} \mathrm{X}-18$ & $\mathrm{C}-18,{ }^{0,4} \mathrm{~A}-18,{ }^{1,3} \mathrm{~A}$ & $1-3$ and $1-4$ & ${ }^{0,2} \mathrm{~A}-18,{ }^{0,4} \mathrm{X} / \mathrm{Z}-\mathrm{H}$ \\
\hline $1-3$ & ${ }^{0,3} \mathrm{X}$ & No cross-ring fragments & $1-3$ and $1-6$ & $\mathrm{C}-18,{ }^{0,3} \mathrm{~A},{ }^{0,4} \mathrm{~A}$ \\
\hline $1-4$ & ${ }^{0,2} \mathrm{~A}-18$ & ${ }^{0,2} \mathrm{~A},{ }^{0,2} \mathrm{~A}-18$ & $1-4$ and $1-6$ & ${ }^{0,2} \mathrm{~A}-18,{ }^{0,3} \mathrm{~A} / \mathrm{W}$ \\
\hline $1-6$ & ${ }^{0,3} \mathrm{~A}$ & $\mathrm{C}-18,{ }^{0,2} \mathrm{~A},{ }^{0,3} \mathrm{~A},{ }^{0,4} \mathrm{~A}$ & & \\
\hline
\end{tabular}

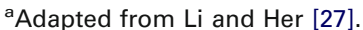


Table 2. Product ions obtained from $\mathrm{MS}^{3}$ of the ABEE closed-ring labeled M5G2 and M6G2 degradation product

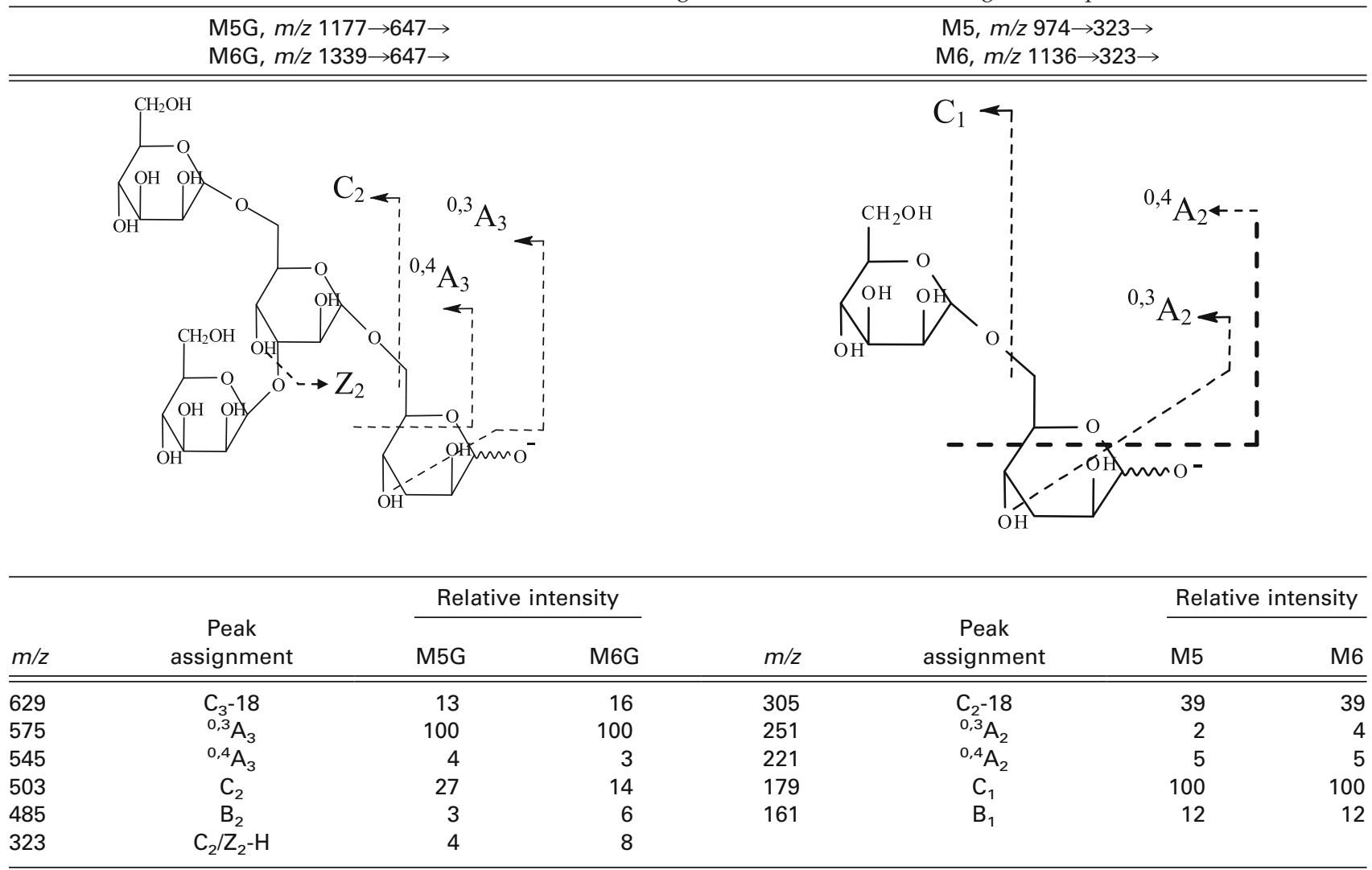

503) fragment, which indicates that there is a second branch point at the fourth saccharide from the reducing end of M5G2. In addition, a hexose residue is 1-3 linked to the second branch point. The intensity of the $C_{2}$ / $\mathrm{Z}_{2}-\mathrm{H}(\mathrm{m} / \mathrm{z} 323)$ ion was too poor for further product ion study; however, a much greater intensity for this ion was obtained from $\mathrm{MS}^{2}$ of the ABEE closed-ring labeled M5 moiety ( $m / z$ 974) (spectrum not shown). The product ions of the $\mathrm{C}_{2} / \mathrm{Z}_{2}-\mathrm{H}(\mathrm{m} / \mathrm{z} 323)$ fragment are shown in
Table 2 (M5, $m / z$ 974 $\left.\rightarrow 323^{\circ} \rightarrow\right)$. The $1-3^{\circ}$ and $1-6$ linkages at the second branch point of M5G2 are revealed by the $\mathrm{C}_{2}-18(\mathrm{~m} / \mathrm{z} 305),{ }^{0,3} \mathrm{~A}_{2}(\mathrm{~m} / \mathrm{z} 251)$ and ${ }^{0,4} \mathrm{~A}_{2}(\mathrm{~m} / \mathrm{z} 221)$ fragments, and the absence of the ${ }^{0,2} \mathrm{~A}_{2}(\mathrm{~m} / \mathrm{z} 281)$ fragment.

Based on the $\mathrm{MS}^{2}$ and $\mathrm{MS}^{3}$ data of the sequential degradation products, M5G and M5, with ABEE closedring labeling, all the sequence, linkages, and branch points of M5G2 could be assigned. The predicted structure is

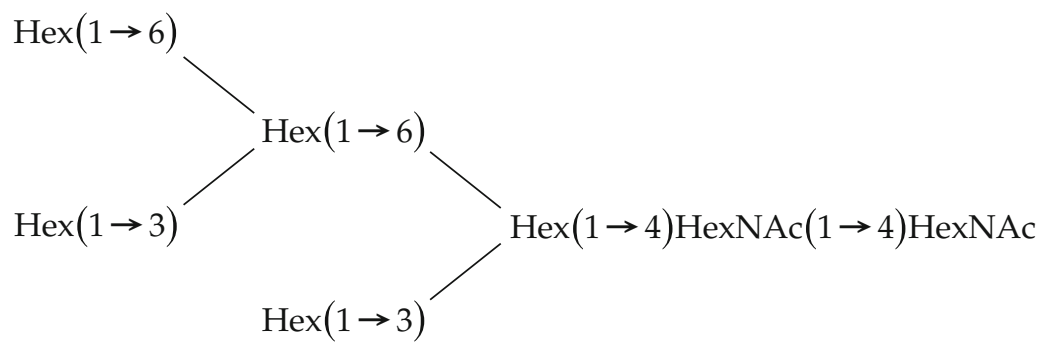

An octasaccharide, M6G2, isolated from ribonuclease B, was also studied. After HPLC separation, the chromophore was removed and the glycan was subjected to alkaline degradation. After a 24-h degradation period in $20 \mathrm{mM} \mathrm{NaOH}$ at $60{ }^{\circ} \mathrm{C}$, M6G2 and its degradation products were labeled with $\mathrm{ABEE}$ and studied by negative ion tandem mass spectrometry.
The $\mathrm{MS}^{2}$ spectrum of the ABEE closed-ring labeled $\operatorname{M6G}^{\circ}(\mathrm{m} / \mathrm{z} 1542){ }^{\circ}{ }^{\circ}{ }^{\circ}$ shown in ${ }^{\circ}$ Figure $2 .{ }^{\circ}$ The $^{0,2} \mathrm{~A}_{5}-18(\mathrm{~m} / \mathrm{z}$ 1276) fragment indicates that the first linkage is a 1-4 linkage. The ${ }^{0,2} \mathrm{~A}_{4}\left(\mathrm{~m} / \mathrm{z}\right.$ 1091) and ${ }^{0,2} \mathrm{~A}_{4}-18(\mathrm{~m} / \mathrm{z} 1073)$ fragments suggest that the second linkage is also a 1-4 linkage. The $\mathrm{C}_{3} / \mathrm{Z}_{3 \beta}-\mathrm{H}$ ion $(\mathrm{m} / \mathrm{z}$ 647) represents the loss of a disaccharide (342 Da) from the terminal $C_{3}(\mathrm{~m} / z$ 989) fragment, which indicates that the hydroxy group 


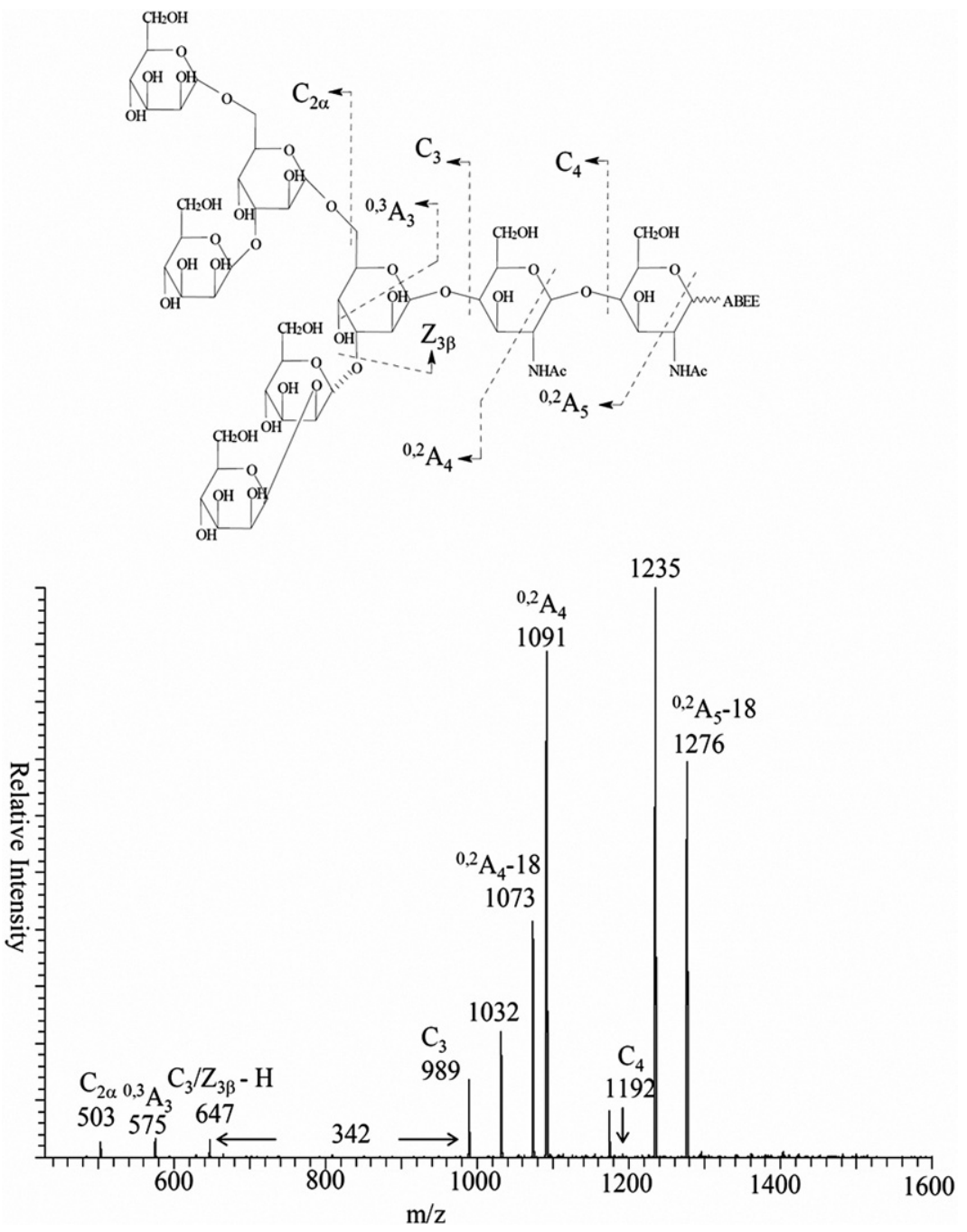

Figure 2. $\mathrm{MS}^{2}$ of the ABEE closed-ring labeled M6G2, $m / z 1542 \rightarrow$.

at the 3 position of the branched sugar is substituted with a disaccharide residue. Other linkages in the upper arm can be assigned by the $\mathrm{MS}^{3}$ spectrum of the $\mathrm{m} / \mathrm{z} 647$ tetrasaccharide ion. However, the intensity of the $\mathrm{m} / \mathrm{z}$ 6479on in Figure 2'was not'sufficient'for'further'product ion analysis. Therefore, the first degradation product ABEE labeled M6G was subsequently selected for $\mathrm{MS}^{2}$ and $\mathrm{MS}^{3}$ experiments.

The $\mathrm{MS}^{2}$ spectrum of the ABEE closed-ring labeled

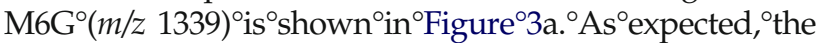
${ }^{0,2} \mathrm{~A}_{4}-18(\mathrm{~m} / \mathrm{z}$ 1073) fragment indicates a 1-4 linkage for the second linkage of M6G2. A 1-3 linkage is revealed by the detection of the $\mathrm{C}_{3} / \mathrm{Z}_{2 \beta}-\mathrm{H}$ ion $(\mathrm{m} / \mathrm{z}$ 647). The intensity of the ${ }^{\circ} \mathrm{m} / \mathrm{z} 647^{\circ}$ ion $^{\circ}$ was $^{\circ}$ significantly $^{\circ}$ higher $^{\circ}$ than $^{\circ}$ in ${ }^{\circ}$ Figure $^{\circ} 2$ and the ion was selected for $\mathrm{MS}^{3}$ study. The result of this $\mathrm{MS}^{3^{\circ}}$ study $^{\circ}\left(\mathrm{M} 6 \mathrm{G}, \mathrm{m} / \mathrm{z} 1339^{\circ} \rightarrow{ }^{\circ} 647^{\circ} \rightarrow\right)^{\circ}$ is $^{\circ}$ shown in Table 2 . The ions at $m / z 629\left(\mathrm{C}_{3}-18\right), m / z 575\left({ }^{0,3} \mathrm{~A}_{3}\right), m / z 545\left({ }^{0,4} \mathrm{~A}_{3}\right)$ and the absence of $\mathrm{a}^{0,2} \mathrm{~A}(\mathrm{~m} / \mathrm{z} 605)$ ion suggest that there is a 1-3 and 1-6 branched sugar. The 1-3 linkage in the 1-3 and 1-6 branched sugar is also supported by the detection of the $\mathrm{C}_{3} / \mathrm{Z}_{3 \beta}-\mathrm{H}^{\circ}$ ion ${ }^{\circ}$ in ${ }^{\circ}$ Figure ${ }^{\circ}{ }^{\circ}$ and ${ }^{\circ}$ the ${ }^{\circ} \mathrm{C}_{3} / \mathrm{Z}_{2 \beta}-\mathrm{H}^{\circ}$ ion ${ }^{\circ}$ in Figure 3 a. ${ }^{\circ} \mathrm{The}^{\circ} \mathrm{C}_{2} / \mathrm{Z}_{2}-\mathrm{H}(\mathrm{m} / \mathrm{z} 323)$ fragment represents the loss of a hexose from the terminal trisaccharide $C_{2}(\mathrm{~m} / \mathrm{z}$ 503) fragment. The presence of the $m / z 323$ ion $\left(\mathrm{C}_{2} / \mathrm{Z}_{2}-\mathrm{H}\right)$ indicates that there is a second branch point in M6G2 and a hexose residue is 1-3 linked to the second branch point.

To obtain a higher-intensity $\mathrm{C}_{2} / \mathrm{Z}_{2}-\mathrm{H}(\mathrm{m} / \mathrm{z} 323)$ ion for product ion study, the ABEE labeled M6 (m/z 1136) was subjected ${ }^{\circ}$ to $^{\circ} \mathrm{MS}^{2^{\circ}}$ study $^{\circ}\left(\right.$ Figure $\left.^{\circ} 3 \mathrm{~b}\right) .^{\circ}$ The $^{\circ}$ first $^{\circ}$ branch $^{\circ}$ of M6G2 is revealed by the detection of the ion at $\mathrm{m} / \mathrm{z} 794$ $\left(\mathrm{Z}_{1 \beta}-\mathrm{H}\right)$, which represents the loss of a 1-3 linked disaccharide (342 Da) from the precursor ion $(\mathrm{m} / z$ 1136). The second branch is indicated by the observation of the ion at $m / z 323\left(\mathrm{C}_{2 \alpha} / \mathrm{Z}_{2 \alpha^{\prime}}-\mathrm{H}\right)$. The $m / z 323$ ion $\left(\mathrm{C}_{2 \alpha} / \mathrm{Z}_{2 \alpha^{\prime}}-\mathrm{H}\right)$ represents the loss of a 1-3 linked hexose from the terminal branched trisaccharide $C_{2 \alpha}$ ion $(m / z 503)$. The linkages at the second branch were assigned by the product ions of the $\mathrm{C}_{2 \alpha^{\prime}} / \mathrm{Z}_{2 \alpha^{\prime}} \mathrm{H}^{\circ}(\mathrm{m} / \mathrm{z} 323)^{\circ}$ ion $^{\circ}$ (shown ${ }^{\circ}$ in $^{\circ} \mathrm{Table}^{\circ}{ }^{\circ},{ }^{\circ} \mathrm{M} 6,{ }^{\circ} \mathrm{m} / \mathrm{z}$ $1136 \rightarrow 323 \rightarrow)$. The ions at $m / z 305\left(\mathrm{C}_{2}-18\right), m / z 251\left({ }^{0,3} \mathrm{~A}_{2}\right)$, and $m / z 221\left({ }^{0,4} \mathrm{~A}_{2}\right)$ and the absence of $\mathrm{a}^{0,2} \mathrm{~A}(\mathrm{~m} / \mathrm{z} 281)$ ion suggest that the second branch sugar is 1-3 and 1-6 linked. The 1-3 linkage in the 1-3 and 1-6 branched sugar is also supported by the $\mathrm{C}_{2} / \mathrm{Z}_{2}-\mathrm{H}$ ion and the $\mathrm{C}_{2 \alpha} / \mathrm{Z}_{2 \alpha^{\prime}}-\mathrm{H}$ ion in 


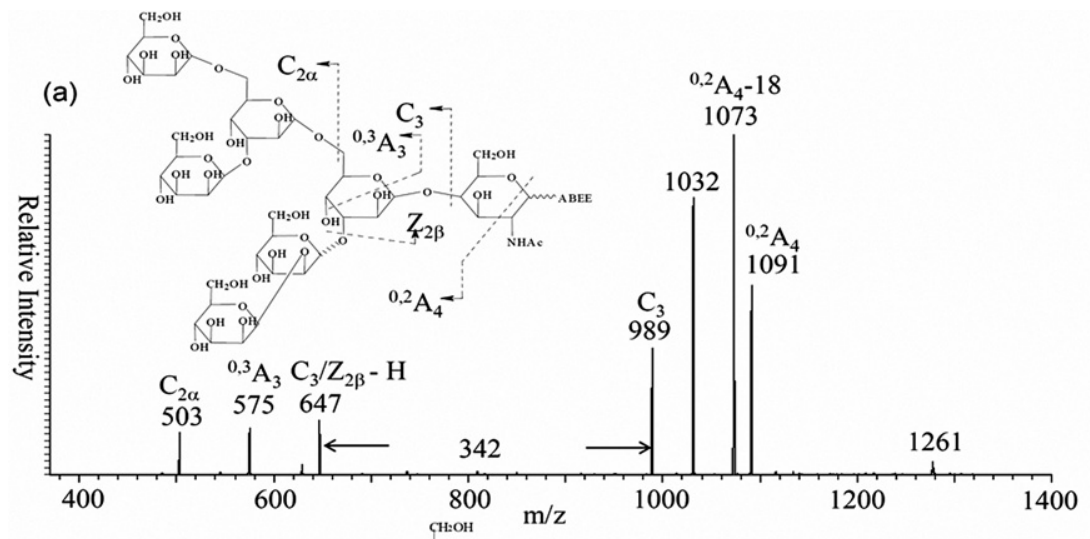

(b)
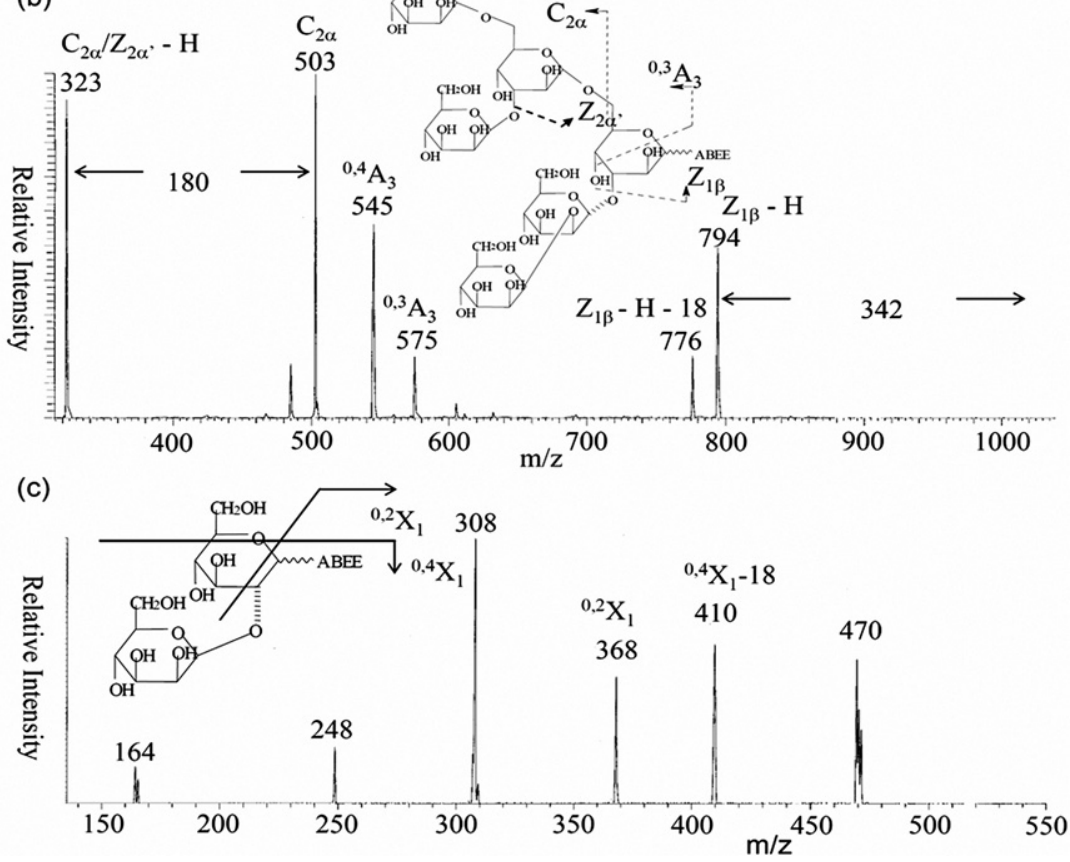

Figure 3. $\mathrm{MS}^{2}$ of the ABEE closed-ring labeled M6G2 degradation product: (a) M6G, $\mathrm{m} / \mathrm{z} 1339 \rightarrow$; (b) M6, $m / z 1136 \rightarrow$; (c) M2, $m / z 488 \rightarrow$.
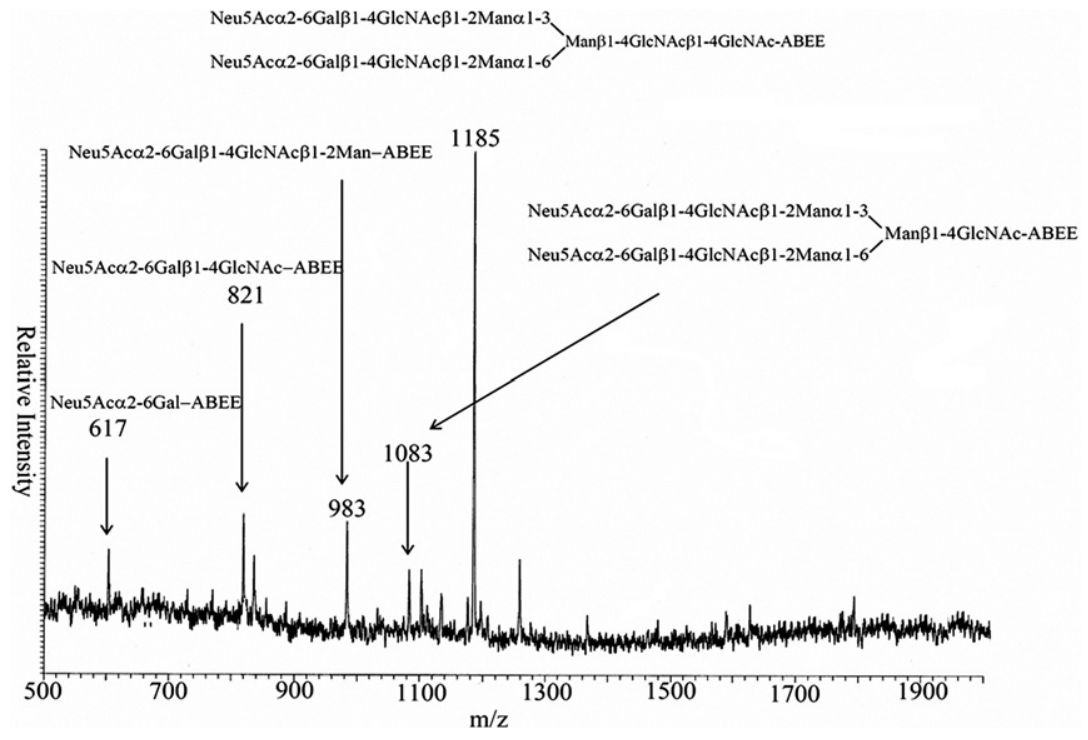

Figure 4. MS spectrum of the ABEE closed-ring labeled A2 and its degradation products. 
Table ${ }^{\circ}\left(\mathrm{M} 6 \mathrm{G},{ }^{\circ} \mathrm{m} / \mathrm{z} 1339^{\circ} \rightarrow{ }^{\circ} 647^{\circ} \rightarrow\right)^{\circ}$ and $^{\circ}{ }^{\circ}$ Figure $3 \mathrm{~b}$, ${ }^{\circ}$ respectively.

Based on the observation of the ion corresponding to the ${ }^{\circ}$ oss $^{\circ}$ of $^{\circ} \mathrm{a}^{\circ}$ disaccharide $^{\circ}\left(\mathrm{m} / z 9^{\circ} 9^{\circ} \rightarrow{ }^{\circ} 647\right)^{\circ}$ in $^{\circ}$ Figure $^{\circ} 2$ and ${ }^{\circ}$ Figure $^{\circ} 3 a^{\circ},{ }^{\circ} \mathrm{M} 6 \mathrm{G}^{\circ}{ }^{\circ}$ has $^{\circ} \mathrm{a}^{\circ} 1-3^{\circ}$ disaccharide ${ }^{\circ}$ linked ${ }^{\circ}$ to the first branch point of the sugar. However, because the charge was carried by the other part of the molecule, the 3-linked disaccharide was not detected and further MS/MS study of the 3-linked disaccharide was not possible. Fortunately, with a longer reaction time $(24 \mathrm{~h})$ the M2 fragment was observed in the degradation products. To obtain the linkage information of the 3-linked disaccharide, the ABEE labeled M2 ( $\mathrm{m} / \mathrm{z} 488)$ ion was selected for a $\mathrm{MS}^{2}$ experiment as shown in Figure ${ }^{\circ}$ c. The ${ }^{\circ}$ presence ${ }^{\circ}$ of $^{\circ}$ the ${ }^{\circ}$ ions ${ }^{\circ} a^{\circ} \mathrm{m} / z 410^{\circ}\left({ }^{0,4} \mathrm{X}_{1}-18\right)$, and $m / z 368\left({ }^{0,2} X_{1}\right)$ suggests that the 3-linked disaccharide ${ }^{\circ}$ has $^{\circ} \mathrm{a}^{\circ} 1-2^{\circ}$ linkage ${ }^{\circ}[28]$.

According to $\mathrm{MS}^{2}$ and $\mathrm{MS}^{3}$ spectra of the ABEE closed-ring labeled M6G2 and its degradation products, M6G, M6, and M2, all the linkages and branch points of M6G2 could be assigned. The predicted structure is

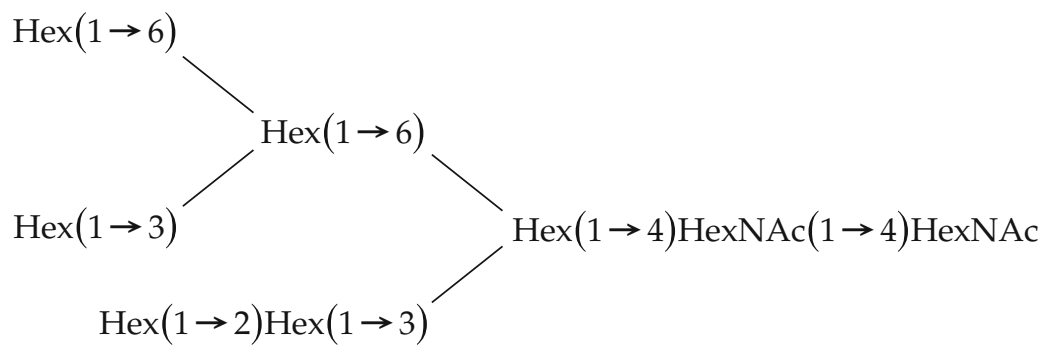

The approach was also applied to a complex oligosaccharide-A2, a sialoglycan obtained from human serum transferrin. Sialoglycans were found to be relatively unstable under labeling conditions as well as alkaline degradation. In ABEE labeling, the loss of sialic acids could be avoided when the reaction temperature was reduced from 90 to $65^{\circ} \mathrm{C}$. Sialic acid was easily dissociated from oligosaccharides even under the mildest degradation condition $(2 \mathrm{mM} \mathrm{NaOH})$. This problem not only complicates the degradation products, but also causes the loss of the linkage information of the sialic acid. To stabilize the sialylated oligosaccharides under alkaline hydrolysis, the 2-alkyl-1,3-oxazoline derivative was used to make sialic acid more stable during alkaline degradation ${ }^{\circ}[48]^{\circ}{ }^{\circ}$ More ${ }^{\circ}$ important, ${ }^{\circ}$ the ${ }^{\circ}$ protecting ${ }^{\circ}$ group can be removed during subsequent ABEE closed-ring labeling.

After 2-alkyl-1,3-oxazoline derivatization, the protected $\mathrm{A} 2$ was heated in $20 \mathrm{mM} \mathrm{NaOH}$ at $60{ }^{\circ} \mathrm{C}$ for $8 \mathrm{~h}$ and then labeled with ABEE. The ESI-MS spectrum of the ABEE closed-ring labeled A2 and its degradation products ${ }^{\circ}$ is $^{\circ}$ shown $^{\circ}$ in $^{\circ}{ }^{\circ}$ igure ${ }^{\circ} 4 .{ }^{\circ}$ The ${ }^{\circ}$ peaks ${ }^{\circ}$ at ${ }^{\circ} \mathrm{m} / z 1185$ and 1083, which are doubly charged ions, represent A2 and its first degradation product, respectively. The ions at $\mathrm{m} / \mathrm{z} 983,821$, and 617 are singly charged ions and represent smaller degradation products. The singly charged ions of A2 and its first degradation product were not detected because the mass range of the ion trap mass spectrometer is limited to $\mathrm{m} / \mathrm{z}$ 2000.

The $\mathrm{MS}^{2}$ spectrum of the ABEE labeled A2 $(\mathrm{m} / \mathrm{z}$ 1185) is ${ }^{\circ}$ shown ${ }^{\circ}{ }^{\circ}$ Figure ${ }^{\circ}$. The ${ }^{\circ} \mathrm{B}_{6}(\mathrm{~m} / \mathrm{z} 1000$, doubly charged) and $\mathbf{B}_{5}(\mathrm{~m} / z$ 898, doubly charged) fragments in dicate that both the reducing end and the adjacent monosaccharide are $\mathrm{N}$-acetylhexosamines. The presence of the
${ }^{0,2} \mathrm{~A}_{7}-18(\mathrm{~m} / \mathrm{z} 1051$, doubly charged) fragment indicates that the first linkage is a 1-4 linkage. The 1-4 linkage of the second HexNAc is revealed by the ${ }^{0,2} \mathrm{~A}_{6}$ $\left(\mathrm{m} / \mathrm{z}\right.$ 958, doubly charged) and the ${ }^{0,2} \mathrm{~A}_{6}-18(\mathrm{~m} / \mathrm{z} 949$, doubly charged) fragments. $\mathrm{A} \mathrm{C}_{5} / \mathrm{Z}_{3 \mathrm{x}}-\mathrm{H}$ fragment at $\mathrm{m} / \mathrm{z} 979$ represents the loss of a tetrasaccharide (Neu5AcHexHexNAcHex, $836 \mathrm{Da}$ ) and an ABEElabeled disaccharide (ABEE-HexNAcHexNAc, 554 $\mathrm{Da})$ from intact A2. The loss of a tetrasaccharide suggests a 1-3 linkage in the branched sugar. The $\mathrm{C}_{5} / \mathrm{Z}_{3 x}-\mathrm{H}(\mathrm{m} / \mathrm{z}$ 979) fragment was subsequently selected for a $\mathrm{MS}^{3}$ experiment and the result is shown in Table $^{\circ} 3^{\circ}\left(\mathrm{A} 2,{ }^{\circ} \mathrm{m} / z 1185^{\circ} \rightarrow{ }^{\circ} 979^{\circ} \rightarrow{ }^{\circ}\right.$. $^{\circ}$ The ${ }^{\circ}$ presence ${ }^{\circ}$ of ${ }^{\circ}$ the $\mathrm{C}_{5}-18\left(\mathrm{~m} / \mathrm{z}\right.$ 961), ${ }^{0,3} \mathrm{~A}_{5}\left(\mathrm{~m} / \mathrm{z}\right.$ 907) and ${ }^{0,4} \mathrm{~A}_{5}(\mathrm{~m} / \mathrm{z}$ 878) fragments, and the absence of the ${ }^{0,2} \mathrm{~A}_{5}(\mathrm{~m} / \mathrm{z}$ 938) fragment suggest that the branched sugar has a 1-3 and 1-6 linkage.

The CID spectrum of the ABEE labeled tetrasaccharide $^{\circ}\left(\mathrm{m} / z \text { } 983^{\circ} \text { ion }\right)^{\circ}$ is ${ }^{\circ}$ shown $^{\circ}$ in $^{\circ}$ Figure $^{\circ} 6 a .^{\circ}$ The $^{\circ}$ observation of the diagnostic ion at $\mathrm{m} / \mathrm{z} 862\left({ }^{0,2} \mathrm{X}_{1}\right)$ indicates that the first linkage is a 1-2 linkage. The second linkage of the tetrasaccharide is not clear in Figure ${ }^{\circ} 6 a^{\circ}$ and ${ }^{\circ}$ therefore ${ }^{\circ}$ was $^{\circ}$ determined ${ }^{\circ}$ by $^{\circ}$ the ${ }^{\circ} \mathrm{CID}$ study of the ABEE-labeled trisaccharide $(\mathrm{m} / \mathrm{z}$ 821) shown ${ }^{\circ}{ }^{\circ}{ }^{\circ}$ igure $^{\circ} 6 \mathrm{~b}^{\circ}{ }^{\circ}$ The ${ }^{\circ}$ product ${ }^{\circ}$ ion ${ }^{\circ}$ spectrum ${ }^{\circ}$ of ${ }^{\circ}$ the $\mathrm{m} / \mathrm{z} 821$ ion suggests that the first linkage (the second linkage of the tetrasaccharide) is a 1-4 linkage because the ${ }^{0,2} \mathrm{~A}_{3}-18(\mathrm{~m} / \mathrm{z} 554)$ fragment was observed. Even ${ }^{\circ}$ though ${ }^{\circ}$ the $^{\circ}$ mass $^{\circ}$ of ${ }^{\circ}$ the ${ }^{\circ}$ trisaccharide ${ }^{\circ}$ precursor ion is only around $800 \mathrm{Da}$, the linkage of the sialic acid cannot be determined by its CID spectrum (Figure $\left.{ }^{\circ} 6 \mathrm{~b}\right)^{\circ}$ because $^{\circ}$ only $^{\circ} a^{\circ}$ linkage ${ }^{\circ}$ nonspecific ${ }^{\circ} B_{1}$ ion was observed. Fortunately, many fragments were observed in the CID spectrum of the ABEE labeled disaccharide ${ }^{\circ} a^{\circ} \mathrm{m} / \mathrm{z} 617^{\circ}$ (Figure $\left.{ }^{\circ} 6 \mathrm{c}\right){ }^{\circ}{ }^{\circ}$ The ${ }^{\circ}$ presence ${ }^{\circ}$ of 


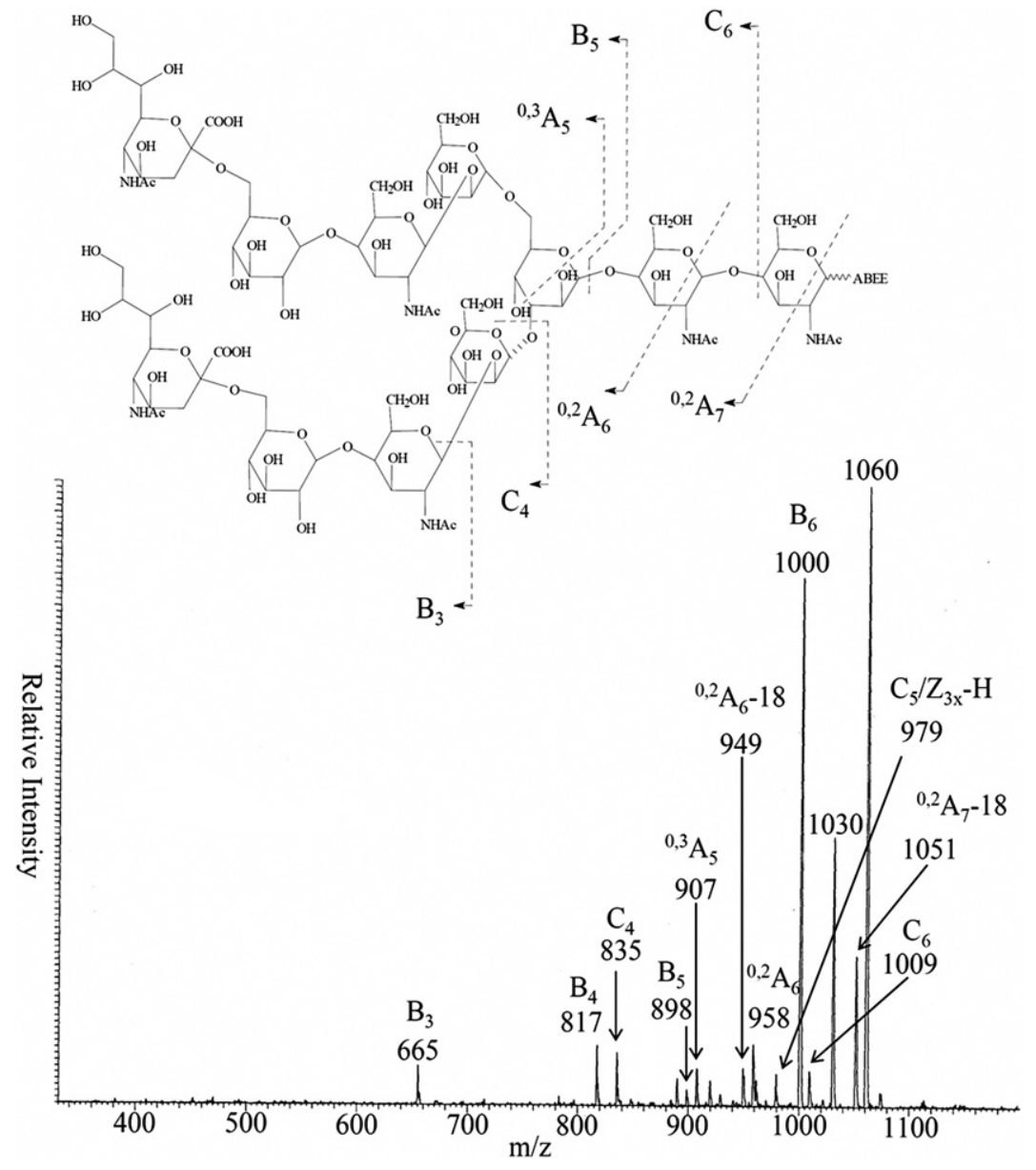

Figure 5. $\mathrm{MS}^{2}$ of the ABEE closed-ring labeled A2, $m / z 1185 \rightarrow$.

Table 3. Product ions obtained from $\mathrm{MS}^{3}$ of the ABEE closedring labeled A2

\begin{tabular}{|c|c|c|}
\hline \multicolumn{3}{|c|}{$\mathrm{A} 2, \mathrm{~m} / \mathrm{z} 1185 \rightarrow 979 \rightarrow$} \\
\hline & $\mathrm{VH}^{\mathrm{OH}}$ & $\begin{array}{c}\mathrm{A}_{5} \\
\vdots \\
\vdots \\
\vdots\end{array}$ \\
\hline$m / z$ & $\begin{array}{c}\text { Peak } \\
\text { assignment }\end{array}$ & $\begin{array}{l}\text { Relative } \\
\text { intensity }\end{array}$ \\
\hline 961 & $C_{5}-18$ & 100 \\
\hline 907 & ${ }^{0,3} A_{5}$ & 16 \\
\hline 878 & ${ }^{0,4} A_{5}$ & 8 \\
\hline 835 & $\mathrm{C}_{4}$ & 22 \\
\hline 817 & $\mathrm{~B}_{4}$ & 28 \\
\hline 655 & $\mathrm{~B}_{3}$ & 14 \\
\hline
\end{tabular}

the ${ }^{0,2} \mathrm{~A}_{2}(m / z 410),{ }^{0,3} \mathrm{~A}_{2}(m / z 380)$, and ${ }^{0,4} \mathrm{~A}_{2}(m / z 350)$ fragments ${ }^{\circ}{ }^{\circ}{ }^{\circ}$ Figure $^{\circ} 6 \mathrm{c}^{\circ}$ suggested ${ }^{\circ}$ that ${ }^{\circ}$ the ${ }^{\circ}$ linkage ${ }^{\circ}$ at the nonreducing end is more likely a 2-6 linkage. To further prove our tentative assignment, 2-3 and 2-6 linked standard compounds by the alkaline degradation of $3^{\prime}$-sialyllactose and 6 '-sialyllactose, respectively, were labeled with $\mathrm{ABEE}$ and analyzed by CID. The $^{\circ}$ result $^{\circ}\left(\text { Table }^{\circ} 4\right)^{\circ}$ showed $^{\circ}$ that $^{\circ}$ the $^{\circ}$ product $^{\circ}$ ions were quite different. The informative fragments are ${ }^{0,3} \mathrm{X}_{1}(\mathrm{~m} / \mathrm{z} 527)$ for $\alpha 2-3$ linkage and ${ }^{0,2} \mathrm{~A}_{2}(\mathrm{~m} / \mathrm{z} 410)$, ${ }^{0,3} \mathrm{~A}_{2}(m / z 380)$, and ${ }^{0,4} \mathrm{~A}_{2}(m / z$ 350) for $\alpha 2-6$ linkage. These fragments conclusively allowed the assignment of the linkages of sialic acid. The presence of the ${ }^{0,2} \mathrm{~A}_{2}$ $(m / z 410),{ }^{0,3} \mathrm{~A}_{2}(m / z 380)$, and ${ }^{0,4} \mathrm{~A}_{2}(m / z 350)$ fragments clearly indicates that the linkage at the nonreducing end in tetrasaccharide is 2-6 linked. It is worth mentioning that without ABEE labeling the product ions mass spectra of 2-3 and 2-6 disaccharides were different mainly in relative intensity but not in fragmentation.

All linkages of the tetrasaccharide were determined by the CID spectra of the ABEE-labeled tetrasaccharide, trisaccharide, $^{\circ}$ and $^{\circ}$ disaccharide $^{\circ}\left(\right.$ Figure $^{\circ} 6 \mathrm{a},{ }^{\circ} \mathrm{b},{ }^{\circ}$ and $^{\circ} \mathrm{c}$, respectively). The observation of no pentasaccharide 
(a)

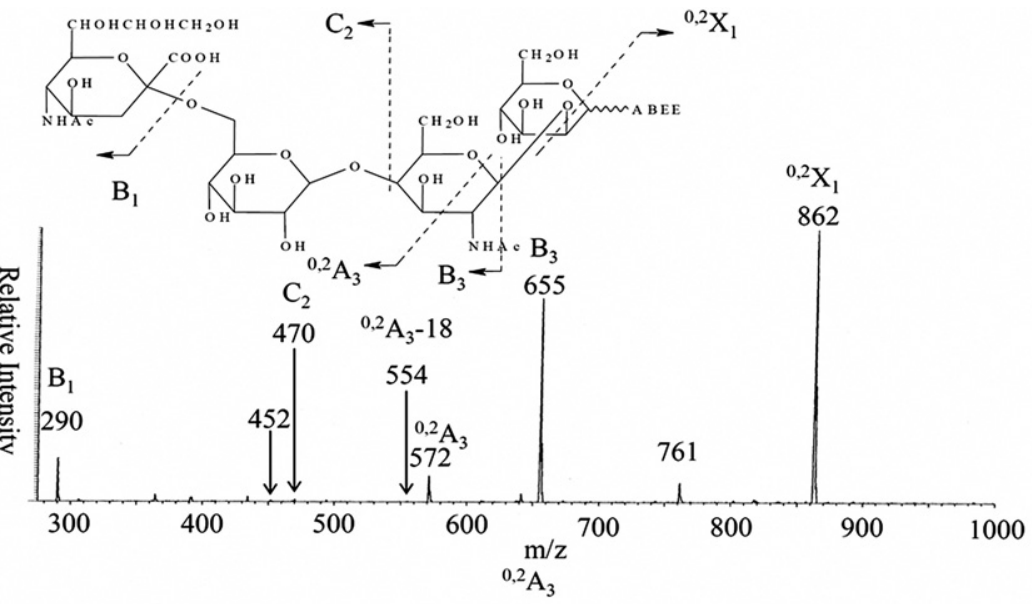

(b)

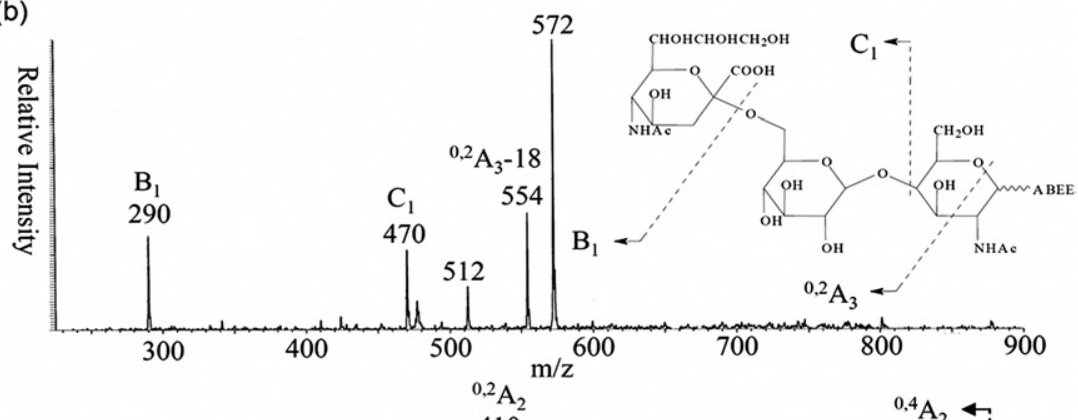

(c)

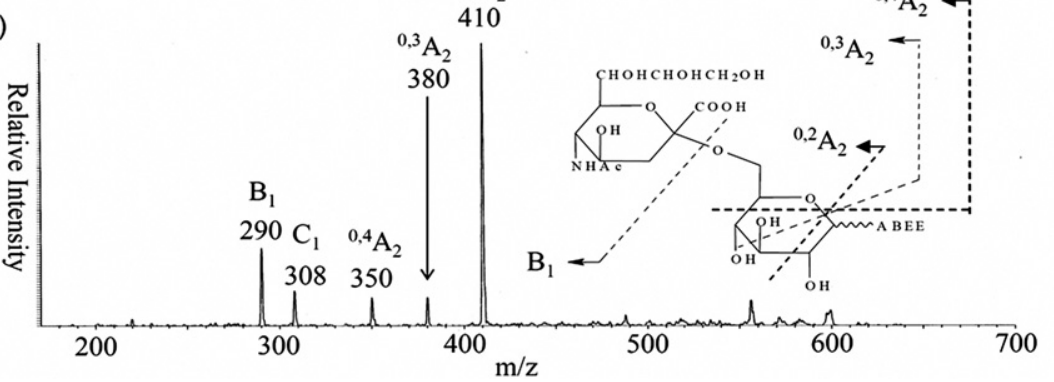

Figure 6. $\mathrm{MS}^{2}$ of the ABEE closed-ring labeled A2 degradation product: (a) $m / z 983 \rightarrow$; (b) $m / z 821$ $\rightarrow$; (c) $m / z 617 \rightarrow$.

and hexasaccharide fragments in the degradation prod-

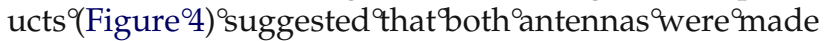
up of tetrasaccharides. Moreover, the detection of only one type of linkage-specific fragment for each linkage suggested that the linkages of the two antennas were the same. With the above information and with the linkage information provided by the $\mathrm{MS}^{2}$ and $\mathrm{MS}^{3}$ spectra of ABEE labeled intact $\mathrm{A} 2$ and its degradation products, all the linkages of the sialylated oligosaccharide A2 were assigned. The predicated structure is

$$
\begin{aligned}
& \operatorname{Neu} 5 \mathrm{Ac}(2 \rightarrow 6) \mathrm{Hex}(1 \rightarrow 4) \mathrm{HexNAc}(1 \rightarrow 2) \mathrm{Hex}(1 \rightarrow 6) \\
& \operatorname{Neu} 5 \mathrm{Ac}(2 \rightarrow 6) \mathrm{Hex}(1 \rightarrow 4) \mathrm{HexNAc}(1 \rightarrow 2) \mathrm{Hex}(1 \rightarrow 3)
\end{aligned}
$$

\section{Conclusions}

An approach was proposed to determine the linkages and branch points of $\mathrm{N}$-linked oligosaccharides. The sequence of the analysis includes ABEE closed-ring labeling, HPLC separation, ABEE delabeling, sequential degradation, ABEE closed-ring relabeling, and $\mathrm{MS}^{2}$ and/or $\mathrm{MS}^{3}$ analysis. Sequential degradation from the reducing end was found to be critical for the linkage information near the nonreducing end. Sequential deg- 
Table 4. Product ions obtained from $\mathrm{MS}^{2}$ of the ABEE closed-ring labeled Neu5Ac $\alpha 2-3 \mathrm{Gal}$ and Neu5Ac $\alpha 2-6 \mathrm{Gal}$

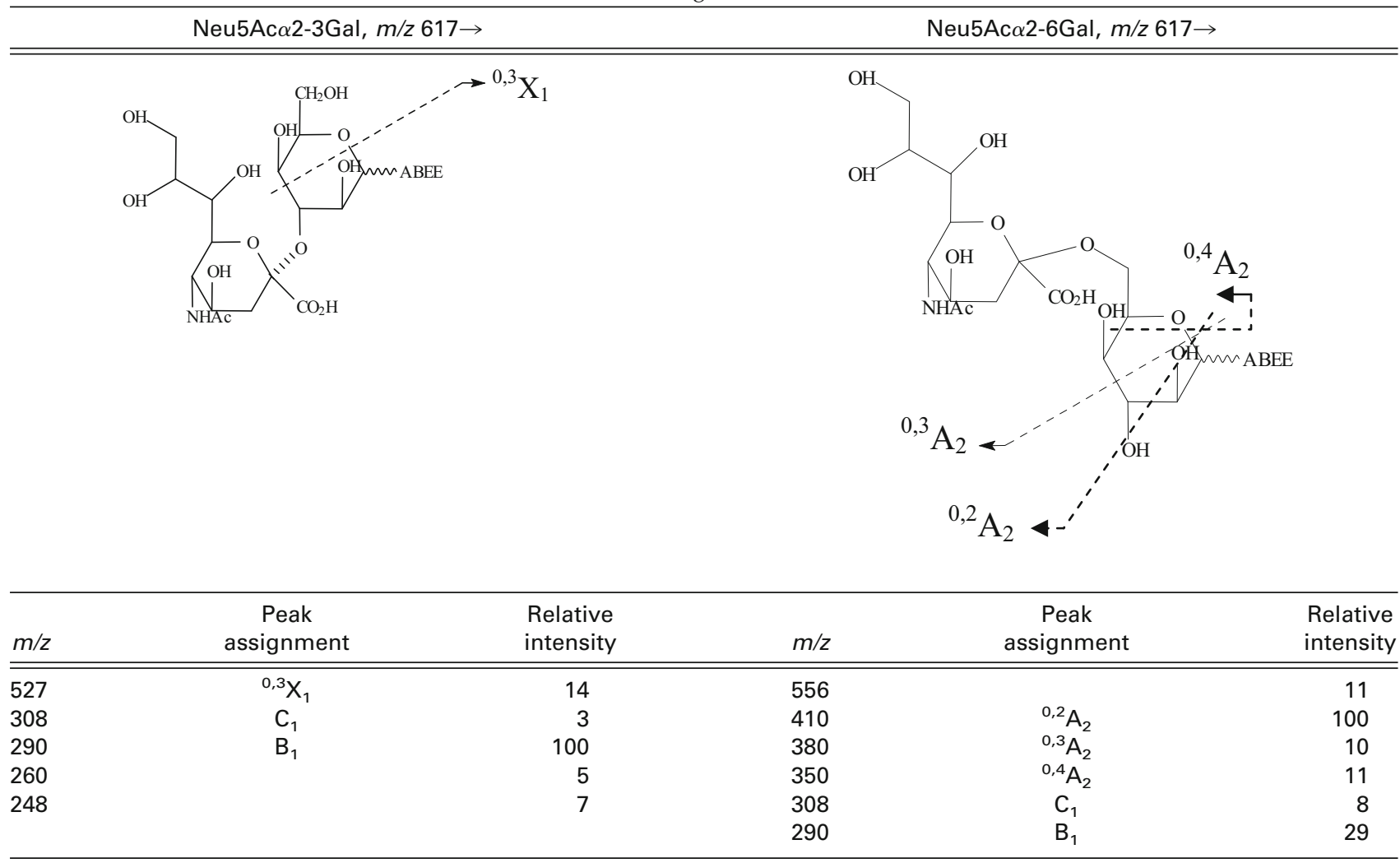

radation is also essential for determination of other linkages if a 3-linkage is present in the oligosaccharide and the 3-linked moiety contains another linkage. All the linkages could be gradually determined based on $\mathrm{MS}^{2}$ and $\mathrm{MS}^{3}$ of ABEE closed-ring labeled oligosaccharide and its degradation products. It is important to note that for sialylated oligosaccharides, sialic acid residues were found to be unstable during labeling and degradation. Lower labeling reaction temperature and the formation of a 2-alkyl-1,3-oxazoline derivative provided a solution to this problem. Although the amount of sample used in this study is in the range of 10 to 20 nmol, the sensitivity of the approach is estimated to be about $1 \mathrm{nmol}$ (ribonuclease B). It was found that alkaline degradation is the key step affecting the overall sensitivity. Without the step of alkaline degradation, the amount of glycoprotein used could be down to 50 pmol. Therefore, further improvement in alkaline degradation would enhance the capability of this approach to work with a low level of glycoproteins.

\section{Acknowledgments}

This work was supported by the National Research Council of the Republic of China.

\section{References}

1. Varki, A. Biological Roles of Oligosaccharides: All of the Theories Are Correct. Glycobiology 1993, 3, 97-130.

2. Dwek, R. A. Glycobiology: Toward Understanding the Function of Sugars. Chem. Rev. 1996, 96, 683-720.
3. Kukuruzinska, M. A.; Lennon, K. Protein N-Glycosylation: Molecular Genetics and Functional Significance. Crit. Rev. Oral. Biol. Med. 1998, 9, 415-448.

4. Helenus, A.; Aebi, M. Intracellular Functions of N-Linked Glycans. Science 2001, 291, 2364-2369.

5. Chaplin, M. F.; Kennedy, J. F. Carbohydrate Analysis; Oxford Univ. Press: New York, 1994; pp 221-289.

6. Harvey, D. J.; Küster, B.; Naven, T. J. P. Perspectives in the Glycosciences: Matrix-Assisted Laser Desorption/Ionization (MALDI) Mass Spectrometry of Carbohydrates. Glycoconjugate J. 1998, 15, 333-338.

7. Tseng, K.; Hedrick, J. L.; Lebrilla, C. B. Catalog-Library Approach for the Rapid and Sensitive Structural Elucidation of Oligosaccharides. Anal. Chem. 1999, 71, 3747-3754.

8. Mechref, Y.; Novotny, M. V.; Krishnan, C. Structural Characterization of Oligosaccharides Using MALDI-TOF/TOF Tandem Mass Spectrometry. Anal. Chem. 2003, 75, 4895-4903.

9. Spina, E.; Sturiale, L.; Romeo, D.; Impallomeni, G.; Garozzo, D.; Waidelich, D.; Glueckmann, M. New Fragmentation Mechanisms in MatrixAssisted Laser Desorption/Ionization Time-of-Flight/Time-of-Flight Tandem Mass Spectrometry of Carbohydrates. Rapid Commun. Mass Spectrom. 2004, 18, 392-398.

10. Wuhrer, M.; Deelder, A. M. Negative-Mode MALDI-TOF/TOF-MS of Oligosaccharides Labeled with 2-Aminobenzamide. Anal. Chem. 2005, 77, 6954-6959.

11. Morelle, W.; Slomianny, M. C.; Diemer, H.; Schaeffer, C.; Dorsselaer A. V.; Michalski, J. C. Structural Characterization of 2-Aminobenzamidederivatived Oligosaccharides Using a Matrix-Assisted Laser Desorption/ Ionization Two-Stage Time-of-Flight Tandem Mass Spectrometer. Rapid Commun. Mass Spectrom. 2005, 19, 2075-2084.

12. Stephens, E.; Maslen, S. L.; Green, L. G.; Williams, D. H. Fragmentation Characteristics of Neutral N-Linked Glycans Using a MALDI-TOF/TOF Tandem Mass Spectrometer. Anal. Chem. 2004, 76, 2343-2354.

13. Lewandrowski, U.; Resemann, A.; Sickmann, A. Laser-Induced Dissociation/High-Energy Collision-Induced Dissociation Fragmentation Using MALDI-TOF/TOF-MS Instrumentation for the Analysis of Neutral and Acidic Oligosaccharides. Anal. Chem. 2005, 77, 3274-3283.

14. Mechref, Y.; Kang, P.; Novotny, M. V. Differentiating Structural Isomers of Sialylated Glycans by Matrix-Assisted Laser Desorption/Ionization Time-of-Flight/Time-of-Flight Tandem Mass Spectrometry. Rapid Commun. Mass Spectrom. 2006, 20, 1381-1389.

15. Sible, E. M.; Brimmer, S. P.; Leary, J. A. Interaction of First Row Transition Metals with a 1-3, a 1-6 Mannotriose, and Conserved Trimannosyl Core Oligosaccharides: A Comparative Electrospray Ionization Study of Double and Singly Charged Complexes. J. Am. Soc. Mass Spectrom. 1997, 8, 32-42. 
16. König, S.; Leary, J. A. Evidence for Linkage Position Determination in Cobalt Coordinated Pentasaccharides Using Ion Trap Mass Spectrometry. I. Am. Soc. Mass Spectrom. 1998, 9, 1125-1134.

17. Reinhold, V. N.; Reinhold, B. B.; Costello, C. E. Carbohydrate Molecular Weight Profiling, Sequence, Linkage, and Branching Data: ES-MS and CID. Anal. Chem. 1995, 67, 1772-1784.

18. Weiskopf, A. S.; Vouros, P.; Harvey, D. J. Characterization of Oligosaccharide Composition and Structure by Quadrupole Ion Trap Mass Spectrometry. Rapid Commun. Mass Spectrom. 1997, 11, 1493-1504.

19. Viseux, N.; de Hoffmann, E.; Domon, B. Structural Assignment of Permethylated Oligosaccharide Subunits Using Sequential Tandem Mass Spectrometry. Anal. Chem. 1998, 70, 4951-4959.

20. Weiskopf, A. S.; Vouros, P.; Harvey, D. J. Electrospray Ionization-Ion Trap Mass Spectrometry for Structural Analysis of Complex N-Linked Glycoprotein Oligosaccharides. Anal. Chem. 1998, 70, 4441-4447.

21. Ahn, Y. H.; Yoo, J. S. Malononitrile as a New Derivatizing Reagent for High-Sensitivity Analysis of Oligosaccharides by Electrospray Ionization Mass Spectrometry. Rapid Commun. Mass Spectrom. 1998, 12, 20112015.

22. Charlwood, J.; Langridge, J.; Tolson, D.; Birrell, H.; Camilleri, P. Profiling of 2-Aminoacridone Derivatized Glycans by Electrospray Ionization Mass Spectrometry. Rapid Commun. Mass Spectrom. 1999, 13, $107-112$.

23. Saba, J. A.; Shen, X.; Jamieson, J. C.; Perreault, H. Effect of 1-Phenyl-3methyl-5-pyrazolone Labeling on the Fragmentation Behavior of Asialo and Sialated N-Linked Glycans under Electrospray Ionization Conditions. Rapid Commun. Mass Spectrom. 1999, 13, 704-711.

24. Shen, X.; Perreault, H. Electrospray Ionization Mass Spectrometry of 1-Phenyl-3-methyl-5-pyrazolone Derivatives of Neutral and N-Acetylated Oligosaccharides. J. Mass Spectrom. 1999, 34, 502-510.

25. Harvey, D. J. Electrospray Mass Spectrometry and Fragmentation of N-Linked Carbohydrates Derivatized at the Reducing Terminus. J. Am. Soc. Mass Spectrom. 2000, 11, 900-915.

26. Her, G. R.; Santikarn, S.; Reinhold, V. N.; Williams, J. C. Simplified Approach to HPLC Precolumn Fluorescent Labeling of Carbohydrates: N-(2-pyridinyl)glycosylamines. J. Carbohydr. Chem. 1987, 6, 129-139.

27. Li, D. T.; Her, G. R. Linkage Analysis of Chromophore-Labeled Disaccharides and Linear Oligosaccharides by Negative Ion Fast Atom Bombardment Ionization and Collisional-Induced Dissociation with B/E Scanning. Anal. Biochem. 1993, 211, 250-257.

28. Li, D. T.; Her, G. R. Structural Analysis of Chromophore-Labeled Disaccharides and Oligosaccharides by Electrospray Ionization Mass Spectrometry and High-Performance Liquid Chromatography/Electrospray Ionization Mass Spectrometry. J. Mass Spectrom. 1998, 33, 644652.

29. Li, D. T.; Sheen, J. F.; Her, G. R. Structural Analysis of ChromophoreLabeled Disaccharides by Capillary Electrophoresis Tandem Mass Spectrometry Using Ion Trap Mass Spectrometry. J. Am. Soc. Mass Spectrom. 2000, 11, 292-300.

30. Cheng, H. L.; Her, G. R. Determination of Linkages of Linear and Branched Oligosaccharides Using Closed-Ring Chromophore Labeling and Negative Ion Trap Mass Spectrometry. J. Am. Soc. Mass Spectrom. 2002, 13, 1322-1330.

31. Lattova, E.; Snovida, S.; Perreault, H.; Krokhin, O. Influence of the Labeling Group on Ionization and Fragmentation of Carbohydrates in Mass Spectrometry. J. Am. Soc. Mass Spectrom. 2005, 16, 683-696.
32. Morelle, W.; Page, A.; Michalski, J. C. Electrospray Ionization Ion Trap Mass Spectrometry for Structural Characterization of Oligosaccharides Derivatized with 2-Aminobenzamide. Rapid Commun. Mass Spectrom. 2005, 19, 1145-1158.

33. Morelle, W.; Faid, V.; Michalski, J. C. Structural Analysis of Permethylated Oligosaccharides Using Electrospray Ionization Quadrupole Time-of-Flight Tandem Mass Spectrometry and Deutero-reduction. Rapid Commun. Mass Spectrom. 2004, 18, 2451-2464.

34. Li, M.; Kinzer, J. A. Structural Analysis of Oligosaccharides by a Combination of Electrospray Mass Spectrometry and Bromine Isotope Tagging of Reducing-End Sugars with 2-Amino-5-Bromopyridine. Rapid Commun. Mass Spectrom. 2003, 17, 1462-1466.

35. Hase, S. Precolumn Derivatization for Chromatographic and Electrophoretic Analyses of Carbohydrates. J. Chromatogr. A 1996, 720, 173-182. 36. Kennedy, J. F. Carbohydrate Chemistry; Clarendon Press: Oxford, U.K., 1988

37. Hong, S. P.; Sano, A.; Nakamura, H. Sequential Analysis of Reducing Oligosaccharides Based on a Chemical Reaction Using 8-Amino-2Naphthalenesulfonic Acid. Anal. Sci. 1997, 13, 473-478.

38. Makino, Y.; Kuraya, N.; Omichi, K.; Hase, S. Classification of Sugar Chains of Glycoproteins by Analyzing Reducing End Oligosaccharides Obtained by Partial Acid Hydrolysis. Anal. Biochem. 1996, 238, 54-59.

39. Makino, Y.; Omichi, K.; Hase, S. Analysis of Oligosaccharide Structures from the Reducing End Terminal by Combining Partial Acid Hydrolysis and a Two-Dimensional Sugar Map. Anal. Biochem. 1998, 264, 172-179.

40. Cancilla, M. T.; Gaucher, S. P.; Desaire, H.; Leary, J. A. Combined Partial Acid Hydrolysis and Electrospray Ionization-Mass Spectrometry for the Structural Determination of Oligosaccharides. Anal. Chem. 2000, 72, 2901-2907.

41. Whistler, R. L.; BeMiller, J. N. Alkaline Degradation of Polysaccharides. In Advances in Carbohydrate Chemistry; Academic Press: New York, 1958; Vol. 13; pp 289-329.

42. Hough, L.; Richardson, A. C. Comprehensive Organic Chemistry; Pergamon Press: Oxford, U.K., 1979; Vol. 5.

43. Cancilla, M. T.; Penn, S. G.; Lebrilla, C. B. Alkaline Degradation of Oligosaccharides Coupled with Matrix-Assisted Laser Desorption/ Ionization Fourier Transform Mass Spectrometry: A Method for Sequencing Oligosaccharides. Anal. Chem. 1998, 70, 663-672.

44. Lee, B. S.; Krishnanchettiar, S.; Lateef, S. S.; Lateef, N. S.; Gupta, S Characterization of Oligosaccharide Moieties of Intact Glycoproteins by Microwave-Assisted Partial Acid Hydrolysis and Mass Spectrometry. Rapid Commun. Mass Spectrom. 2005, 19, 2629-2635.

45. Mo, W.; Takao, T.; Sakamoto, H.; Shimonishi, Y. Structural Analysis of Oligosaccharides Derivatized with 4-Aminobenzoic Acid 2-(Diethylamino)ethyl Ester by Matrix-Assisted Laser Desorption/Ionization Mass Spectrometry. Anal. Chem. 1998, 70, 4520-4526.

46. Lai, C. C.; Her, G. R. Analysis of N-Glycosylation of Phospholipase A from Venom of Individual Bees by Microbore High Performance Liquid Chromatography/Electrospray Mass Spectrometry Using an Ion Trap Mass Spectrometry. J. Chromatogr. B 2002, 766, 243-250.

47. Domon, B.; Costello C. E. A Systematic Nomenclature for Carbohydrate Fragmentations in FAB-MS/MS Spectra of Glycoconjugates. Glycoconjugate J. 1988, 5, 397-409.

48. Vorbüggen, H.; Krolikiewicz, K. A Simple Synthesis of Delta-2oxazolines, Delta-2-oxazines, Delta-2-thiazolines and Delta-2-imidazolines. Tetrahedron Lett. 1981, 22, 4471-4474. 